\title{
A study on the metaphor of social exclusion from embodied cognition
}

\author{
Zeng Wang and Zhong-Yi Lu* \\ Department of Psychology, School of Education, Hebei Normal University, Shijiazhuang 050091, China. \\ Accepted 10 December, 2010
}

\begin{abstract}
The research seeks to further understand the metaphor between social exclusion and coldness. In study 1, participants primed with social exclusion estimated that food contains more calories, compared with participants in the control condition, while in study 2, participants categorized words presented on a computer screen. However, social exclusion words were categorized more quickly in the cold font than in the hot font. These findings are consistent with the embodied cognition theory. The research demonstrates that the priming of social exclusion induces an actual feeling of coldness, and the connection between social exclusion and physical coldness is automatic and unconscious.
\end{abstract}

Key words: Conceptual metaphor, embodied cognition, social exclusion, temperature, psycholinguistics, social cognition, cognitive psychology.

\section{INTRODUCTION}

The association between social exclusion and physical coldness exists in different languages, such as English and Chinese. The theory of 'conceptual metaphor' holds that metaphor is not merely a linguistic phenomenon, but a cognitive matter (Lakoff and Johnson, 1980). Metaphor allows people to think abstractly because it links abstract concepts to concrete sensory experiences, for example, social exclusion is physical coldness (Zhong and Leonardelli, 2008), good is up (Meier and Robinson, 2004), bad is down (Meier and Robinson, 2006), powerful is up (Schubert, 2005), and morality is cleanliness (Schnall et al., 2008; Zhong and Liljenquist, 2006). Without such links, concepts would lack reference to the physical world and it would be difficult to communicate to other people (Lakoff and Johnson, 1999).

Arsh found that some personality traits (such as generous, sociable, popular, and humane) are related to hot-cold dimension (Asch, 1946). In Williams and Bargh's study (Williams and Bargh, 2008a), participants who held a cup of hot coffee assessed a target person much warmer than participants who held a cup of cold coffee. In a recent study by Zhong and Leonardelli (2008),

\footnotetext{
${ }^{*}$ Corresponding author. E-mail: luzhongyi@mail.hebtu.edu.cn. Tel: +86 13833125857
}

participants who recalled a social exclusion experience estimated room temperature lower than the participants in the control condition. We conducted a study to further understand the metaphor between social exclusion and physical coldness, and we tested whether the connection between social exclusion and physical coldness is automatic or unconscious.

\section{METHODOLOGY}

\section{Study 1}

Study 1 examined whether the priming of social exclusion will result in an actual feeling of coldness by estimating food calories. We predicted that participants primed with social exclusion, compared with participants in the control condition, would feel colder and estimate food to contain more calories.

This experiment argues that if social exclusion could induce physical coldness, the participants, at this very moment, would need to eat food with more calories so as to keep out of cold, and that if they were asked to estimate how many calories the present food contained, the participants who felt cold would overestimate the number of calories contained in the food.

\section{Participants}

A total of 44 undergraduates from Hebei Normal University took part 

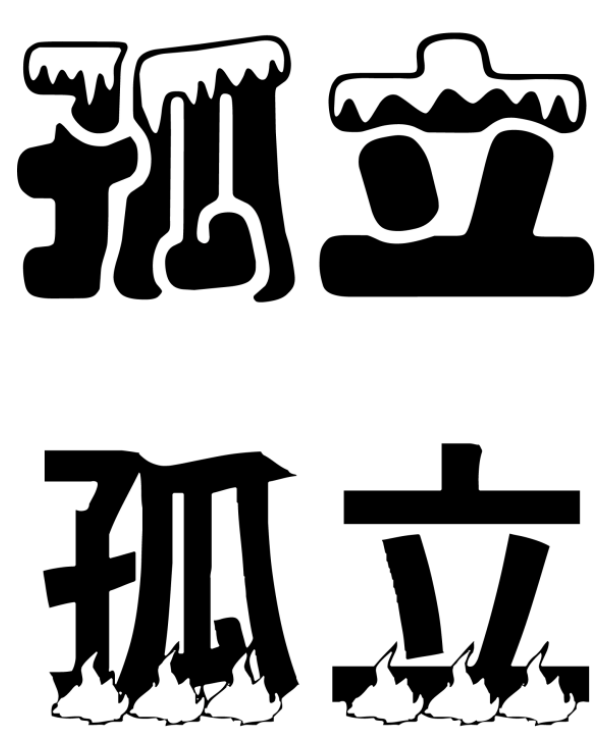

Figure 1. Example of words presented in Study 2.
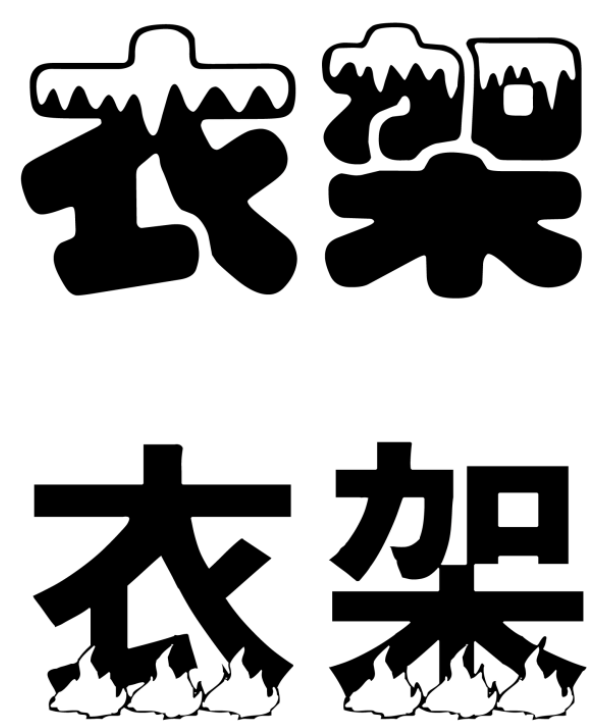

in the experiment.

\section{Materials and procedure}

In this study, we primed people with a scrambled-sentences task (Costin, 1969; Schnall et al., 2008). Participants were asked to complete a scrambled-sentences task involving 40 sets of four words each (in Chinese). By underlining any three words in a set, a sentence could be formed. In the exclusion condition, half of the sets contained words related to the theme of social exclusion (for example, rejection and discrimination), and the other sets contained only neutral words. In the control condition, all 40 sets contained only neutral words.

Subsequently, participants were instructed to estimate the number of calories of a hamburger on the table, with range from 0 to 600 calories (Williams and Bargh, 2008b), although they were not aware of the experimental hypothesis.

\section{Study 2}

In study 2, we tested whether the connection between social exclusion and physical coldness is automatic and unconscious. If so, conceptual processing of social exclusion would be facilitated by the presentation of cold-related cues. In the study, participants were asked to categorize social exclusion and control words that appeared in a font suggestive of either hot or cold temperatures; and we predicted that participants categorized social exclusion words more quickly when they are paired with fonts suggestive of cold temperatures.

\section{Participants}

A total of 25 undergraduates from Hebei Normal University took part in the experiment.

\section{Materials and procedure}

Study 2 was completed using Pentium-IV computers with the
Windows XP operating system and E-Prime software (Version 2.0). The experimental stimuli were 10 social exclusion words in Chinese (for example, rejection and discrimination), while the control stimuli were 10 furniture-related words in Chinese (for example, bookcase and mattress). However, there was no difference between social exclusion words and control words in terms of word frequency or word length ( $p s>0.50)$.

Participants were taken to the laboratory, and were told that the experiment concerned how people categorize words in different fonts. The font of the words was suggestive of either a hot or cold temperature (Figure 1). All the words were in black and white (Wilkowski et al., 2009) and each word was presented at the center of a computer screen. Participants were told that font appearance was a task-irrelevant information and they were asked to ignore the information. Participants were instructed to categorize each word for social-interactions-related or furniture-related as quickly and accurately as possible, by pressing one of the two keys on the keyboard (1-key and 0-key). Consequently, the response options (1-key and 0-key) were counterbalanced across participants. Correct trials were separated by a blank screen for $200 \mathrm{~ms}$, and if participants were inaccurate, the word "INCORRECT" appeared in red font for 1,500 ms. Each of the words was presented twice in the hot font and twice in the cold font. Stimulus presentation order was generated randomly across participants by the computer, with the constraint that each word/font combination had to appear once before any word/font combination could be repeated (Wilkowski et al., 2009).

\section{RESULTS}

\section{Study 1}

Measurement values, beyond 3 standard deviations in either direction from the mean of participants' assessment result, were considered outliers and as such, were removed. In total, 2 participants' data were removed. Participants in the exclusion condition estimated that the food contained more calories $(M=354.27$; $S D=110.62)$, than participants in the control condition $(\mathrm{M}=284.70$; 
$S D=86.31)$. As a result, $F(1,40)=5.09, p<0.05$ and partial $\eta 2=0.11$. In accordance with the assumption, it suggests that people primed exclusion improves sensitivity to the energy of the food. In addition, social exclusion can induce an actual feeling of physical coldness.

\section{Study 2}

Inaccurate trials were dropped from the analysis $(3.4 \%$ of trials), and because RT data are typically skewed positively, RTs were subsequently log-transformed. Finally, to reduce the undue impact of outliers, RTs 2.5 SDs above or below the mean (2.3\% of trials) were replaced with cutoff scores (Robinson, 2007; Wilkowski et al., 2009). Although the analyses involved these logtransformed means, the descriptive statistics was reported in terms of the original millisecond unit for ease of the interpretations. Consequently, A 2 (Word type: social exclusion versus control) $\times 2$ (Cue type: hot versus cold) repeated measures analysis of variance (ANOVA) was performed on the RTs.

The main effect of 'cue type' was significant $[F(1,24)=$ $6.038, p=0.022]$, indicating that participants evaluate the words in the cold font $(M=565.14 \mathrm{~ms})$ faster than in the hot font ( $M=585.30 \mathrm{~ms}$ ), while the main effect of 'word type' was not significant $[F(1,24)=3.503, p=0.073]$. Of utmost importance, the interaction of word type $\times$ cue type was significant $[F(1,24)=12.490, p<0.01$, partial $\eta 2=0.342]$. Participants categorize social exclusion words faster when presented with words in the cold font $(\mathrm{M}=551.24 \mathrm{~ms} ; \mathrm{SD}=72.49 \mathrm{~ms})$, than in the hot font ( $\mathrm{M}$ $=588.84 \mathrm{~ms} ; \mathrm{SD}=76.02 \mathrm{~ms})[\mathrm{F}(1,24)=15.99, \mathrm{p}=$ 0.001]. The variable "cue type" did not influence the categorization of RT for furniture-related words (hot font $M=581.76 \mathrm{~ms}, S D=75.00 \mathrm{~ms}$; cold font $M=579.04 \mathrm{~ms}$, $\mathrm{SD}=71.95 \mathrm{~ms})(\mathrm{F}<1)$. All additional effects in these analyses were not significant (Fs $<1)$.

\section{DISCUSSION}

We find that the abstract concept of social exclusion is related to bodily experiences of physical coldness. These findings are consistent with predictions of embodied cognition theory, and people's social experience is not independent of physical and somatic perception (Barsalou, 2008; ljzerman and Semin, 2009; ljzerman and Semin, 2010; Landau, Meier, and Keefer, 2010; Meier, Robinson and Clore, 2004; Moeller, Robinson, and Zabelina, 2008; Zhong and Leonardelli, 2008). In summary, the findings suggest that the priming of social exclusion induces an actual feeling of coldness, and the connection between social exclusion and physical coldness is automatic and unconscious.

\section{Limitations of the research}

Social exclusion causes physical coldness. However, due to the limitations of the experimental methods, we consider that this effect is weak. Issues concerned need to be further studied, such as "Will social exclusion and physical coldness activate the same brain areas?", conversely, "Can physical coldness give rise to social exclusion?", "Are sufferers of autism more sensitive to physical coldness than normal people?", etc.

\section{REFRENCES}

Asch SE (1946). Forming impressions of personality. J. Abnorm. Soc. Psychol., 41(3): 258-290.

Barsalou LW (2008). Grounded cognition. Annu. Rev. Psychol., 59: 617645.

Costin F (1969). The scrambled sentence test: A group measure of hostility. Educ. Psychol. Meas., 29(2): 461-468.

ljzerman H, Semin GR (2009). The thermometer of social relations: Mapping social proximity on temperature. Psychol. Sci., 20(10): 1214-1220.

ljzerman H, Semin GR (2010). Temperature perceptions as a ground for social proximity. J. Exp. Soc. Psychol., 46(6): 867-873.

Lakoff G, Johnson M (1980). Metaphors we live by. Chicago: University of Chicago Press.

Lakoff G, Johnson M (1999). Philosophy in the flesh: The embodied mind and its challenge to western thought. New York: Basic Books.

Landau MJ, Meier BP, Keefer LA (2010). A metaphor-enriched social cognition. Psychol. Bull., 136(6): 1045-1067.

Meier BP, Robinson MD (2004). Why the sunny side is up: Associations between affect and vertical position. Psychol. Sci., 15(4): 243-247.

Meier BP, Robinson MD (2006). Does "feeling down" mean seeing down? Depressive symptoms and vertical selective attention. J. Res. Pers., 40(4): 451-461.

Meier BP, Robinson MD, Clore GL (2004). Why good guys wear white: Automatic inferences about stimulus valence based on brightness. Psychol. Sci., 15(2): 82-87.

Moeller SK, Robinson MD, Zabelina DL (2008). Personality dominance and preferential use of the vertical dimension of space: Evidence from spatial attention paradigms. Psychol. Sci., 19(4):355-361.

Robinson MD (2007). Lives lived in milliseconds: Using cognitive methods in personality research. In Robbins et al. (Eds.) Handbook of research methods in personality psychology. New York: Guilford Press, pp. 345-359.

Schnall S, Benton J, Harvey S (2008). With a clean conscience: cleanliness reduces the severity of moral judgments. Psychol. Sci., 19(12): 1219-1222.

Schubert TW (2005). Your highness: Vertical positions as perceptual symbols of power. J. Pers. Soc. Psychol., 89(1): 1-21.

Wilkowski BM, Meier BP, Robinson MD, Carter MS, Feltman R (2009). "Hot-headed" is more than an expression: The embodied representation of anger in terms of heat. Emotion, 9(4): 464-477.

Williams LE, Bargh JA (2008a). Experiencing physical warmth promotes interpersonal warmth. Science, 322(5901): 606-607.

Williams LE, Bargh JA (2008b). Keeping one's distance: The influence of spatial distance cues on affect and evaluation. Psychol. Sci., 19(3): 302-308.

Zhong CB, Liljenquist K (2006). Washing away your sins: Threatened morality and physical cleansing. Sci., 313(5792): 1451-1452.

Zhong CB, Leonardelli GJ (2008). Cold and lonely: Does social exclusion literally feel cold? Psychol. Sci., 19(9): 838-842. 